\title{
Estimated annual economic loss from organ condemnation, decreased carcass weight and milk yield due to bovine hydatidosis (Echinococcus granulosus, Batsch, 1786) in Ethiopia
}

\author{
Abebe Fromsa ${ }^{1^{*}}$ and Yilma Jobre ${ }^{2}$ \\ ${ }^{1}$ College of Agriculture and Veterinary Medicine, Jimma University, P.O.Box 307, Jimma, Ethio- \\ pia, abebe.merga@ju.edu.et; afromsa@yahoo.com \\ ${ }^{2}$ Food and Agriculture Organization of the United Nations, Cairo, Egypt, yilma.jobre@fao.org \\ * Corresponding author to whom all correspondences and offprint requests should be addressed: \\ abebe.merga@ju.edu.et; afromsa@yahoo.com
}

\begin{abstract}
Post-slaughter survey data collected over a period of 15 years (1985-1999) by the Faculty of Veterinary Medicine (FVM), Addis Ababa University (AAU) were used as a basis for the analysis of estimation of the economic significance of bovine hydatidosis in Ethiopia. The analysis output revealed a $35.15 \%$ mean annual prevalence of bovine hydatidosis. The total estimated economic loss from organ condemnation, carcass weight and milk yield decrease amounts to 1,691,266,200 ETB (101,203,734 USD). This is equivalent to a loss of 475.40 ETB (28.45 USD) per every infected slaughtered cattle and 249.00 ETB (14.90 USD) per every infected milking cow. The results of the present study showed that hydatidosis is a highly prevalent cattle disease in Ethiopia with considerable direct and indirect economic losses. The magnitude of loss per infected subject warrants the need to mount an integrated nation-wide hydatidosis control program involving public education, canine health care, proper handling and disposal of infected organs, stray dog population management and institution of strict standard operating procedures (SOPs) in slaughterhouses and public health legislative reinforcements. The authors recommend that hydatidosis control program should be designed and implemented in the context on 'One Health' initiative by integrating it with other zoonotic disease control program and in partnerships with animal and public health actors as well as other relevant stakeholders. .
\end{abstract}

Keywords: Echinococcus granulosus, Hydatidosis, economic significance, cattle, Ethiopia

http://dx.doi.org/10.4314/evj.v16i2.1 


\section{Introduction}

Hydatidosis or larval echinococcosis is a cyclzoonotic infection caused by the metacestode stage of Echinococcus granulosus, known to occur in various visceral organs of domestic herbivores and humans. The disease is characterized by the presence of cysts containing numerous tiny protoscoleces that most often develop in the liver and lung, but also in spleen, kidney, heart, CNS and skeletal system as well as other rare sites such as thyroid gland, subcutaneous tissue, body cavity and musculature (Abdel-Hafez and Al-Yaman., 1989; Mendy, 1975).

The disease is known to inflict considerable direct and indirect economic losses in the livestock industry. The direct loss is related to the death, premature slaughter and organs condemnation, while the indirect is result of decreased meat, milk and wool production due to infection (Beller, 1977; Polydorou, 1981; Romazanov, 1983; Ahmadi and Meshkehkar 2011). It was indicated that hydatid cyst in the liver, lung, kidney and heart is the major causes of organ condemnation in slaughterhouses (Asegedech Sirak 1996; Getaw et al., 2010). Previous studies showed a reduction of up to 5\% in meat and $10 \%$ in milk production (Polydorou, 1981), and a 20\% decrease in hide value and $11 \%$ decrease in fecundity (Romazanov, 1983) due to hydatidosis. Estimated global annual overall losses from the burden of human cystic echinococcosis (CE) and livestock-associated losses were reported to be $\$ 1,918,318,955$ and $\$ 2,190,132,464$, respectively (Budke et al., 2006). Previous study conducted in three selected regions of Ethiopia also estimated a loss of at least 20 USD per every hydatid infected animal (Yilma Jobre et al., 1996).

Echinococcus granulosus remains as a cause of a persistent and reemerging problem in low income countries where resources for an intensive control program are not available. Future control programmes for human echinococcosis are also likely to depend on the reduction of transmission of the parasite from animals to humans (Robinson and Dalton, 2009). Echinococcosis has long been considered to be an eradicable disease and eradication of Echinococcus granulosus infections has been achieved in several countries/regions including Iceland, Tasmania, New Zealand, Cyprus and the Falkland Islands as a result of concerted efforts in the field and long-term political support (Jenkins et al. 2005). One of the major drives for hydatid disease control is the huge economic losses inflicted by the disease, the figures of which are not wellknown to farmers and governments of developing countries (Heath, 2006). Therefore, availing national estimates of prevalence and economic impact 
evaluations are essential in analysing the cost-benefits and for prioritization of control measures for cystic echinococcosis (hydatidosis). Even though several fragmented studies have been conducted on hydatidosis in different parts of Ethiopia, particularly through the externship program of the Faculty of Veterinary Medicine (FVM) of Addis Ababa University (AAU), very few attempts were made to estimate the economic loss at the national level based on compiled and aggregated mean prevalence rate of the disease. Therefore, the present study was made to estimate on the economic loss, at a national scale, resulting from organ condemnation, decreased carcass weight and milk yield due to bovine hydatidosis in Ethiopia.

\section{Materials and Methods}

\section{Estimation of annual prevalence rate}

The mean annual prevalence of hydatidosis in Ethiopia, and levels of organ involvement were calculated based on previous slaughterhouse surveys carried out in Addis Ababa (Gemeda, 1988), Awassa (Getachew Jember,1991), Arba Minch (Mohammed Alyie, 1988), Assela (Alemayehu Lemma, 1990; Dessie Shiferaw, 1992; Fekadu Olika, 1997), Bahr Dar (Musie Hailemelekot, 1995; Nebiyou Gesese, 1990), Bale Robe (Woubet Sinishaw, 1988), Debre Berhan (Tsegaye Tadesse, 1995), Dire Dawa (Daniel Ferede, 1995; Woubet Mulugeta, 1987), Gondar (Roman Tiruneh, 1987; Tamene Melkamu, 1986), Jimma (Abduljewad Ahmed, 1988), Kombolcha (Asrat Goshime, 1996; Yilkal Asfaw, 1989), Konso (Fikre Lobago, 1994), Mekele (Hagos Yhidego, 1997), Melgue Wondo (Getahun Demeke, 1987), Nazareth (Yemane Gidey,1990), Nekempte (Feyessa Regassa, 1987) and Wollaita Soddo (Abdul Jelal, 1992, Abel Mersie, 1985).

\section{Estimation of economic losses}

\section{Direct annual economic loss}

The estimated direct annual economic loss due to hydatidosis is computed based on the measurement of the following parameters:

- level of organs (lungs, liver, spleen, kidney and heart) condemnation based on 2.1 above,

- average local retail prices of a healthy organs

- estimation of mean annual slaughter rate of 4,920,635 heads of cattle calculated based on the estimated $620,000,000 \mathrm{~kg}$ annual beef production 
(Alemayehu Mengistu, 2006) and a dressed carcass weight of $126 \mathrm{~kg}$ for Ethiopian zebu cattle (ILCA, 1979).

These parameters were then fed to the following formula in order to compute the economic loss due to organ condemned, as unfit for human consumption, due to cystic echninococcosis.

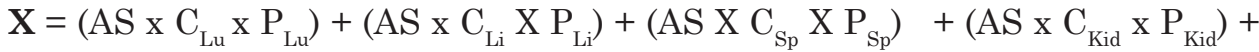
(AS X $\mathrm{C}_{\mathrm{Hr}} \mathrm{X} \mathrm{P}_{\mathrm{Hr}}$ ).

Where: $A S=$ Estimated mean annual kill; $P_{L u}=$ Percent involvement of the lung; $C_{L u}=$ Local retail price of a lung; $P_{L i}=$ Present involvement of the liver; $C_{L i}=$ local retail price of a liver; $P_{S p}=$ Present involvement of the spleen; $C_{S p}=L o c a l$ retail price of a spleen; $P_{K i d}=$ Percent involvement of the kidney; $C_{K i d}=$ Local retail price of a kidney; $P_{H r}=$ Percent involvement of the heart; $C_{H r}=$ Local retail price of a heart

\section{Indirect annual economic loss}

An estimation of the indirect loss due to the decrease in carcass weight and milk yield was made based on the following considerations:

- A reduction of $5 \%$ in meat and $10 \%$ in milk production established by Polydorou (1981)

- The reported $620,000,000 \mathrm{~kg}$ of mean annual meat production (Alemayehu Mengistu, 2006)

- The reported 448 liters of milk production per lactation per head of milking cow (Behnke, 2010)

The above two study reports are actual figures and did not considered the reductions due to any disease entity. The mean annual meat and milk production, in the absence of hydatid disease were thus calculated by multiplying the reported figures by 100/95 and 100/90, respectively. Based on these considerations and the derived mathematical findings, the following input parameters were used to calculate the indirect losses due to hydatidosis:

- The estimated mean annual meat production, in the absence hydatidosis, is $652,631,579 \mathrm{~kg}$.

- $20.6 \%$ of total cattle herd of the country $(48,202,500)$ are milking cows (Behnke, 2010), which is equivalent to 9,929,715 cows

- The estimated milk yield per lactation per cow is 498 liters in the absence of hydatidosis 
- The current mean retail market price of a kilogram of beef is 68 ETB (Muluken Yewondwossen, 2011)

- The current mean retail market price of a liter of milk (5 birr) (Behnke, 2010)

These parameters were computed using the following formula:

$\mathrm{AMP} \times \mathrm{P}_{\mathrm{f}} \times 5 \% \times \mathrm{C}_{\mathrm{Bf}}=$ Economic loss from meat production, Where $A M P=$ estimated mean annual meat production in the absence the disease; $P f=$ Overall prevalence of hydatidosis in cattle; $5 \%=$ Percent reduction in meat caused by hydatidosis; $C_{B f}=$ Mean retail price of a kilogram of beef;

AM x MMY x $\mathrm{P}_{\mathrm{f}} \times 10 \% \times \mathrm{C}_{\mathrm{M}}=$ Economic loss from milk production, Where $A M=$ Annual milking heads of cattle; $M M Y=$ mean annual milk yield per head; $10 \%=$ Percent reduction in milk yield due to hydatidosis and $C_{M}=$ Mean retail price of a liter of milk.

The total annual direct and indirect economic loss due to bovine hydatidosis was then computed as a summation of the losses due to organ condemnation, carcass weight loss and reduced milk yield described herein above.

\section{Results}

\section{Overall prevalence}

From the total of 22863 cattle examined in 18 surveyed abattoirs located in different parts of Ethiopia, 8036 (35.15\%, CI $=34.53-35.77 \%)$ were found harboring hydatid cysts. Besides, 6397(27.98\%), 4211(18.42\%), 392(1.71\%) and $190(0.83 \%)$ of the hydatid cysts were located in the lungs, liver, spleen, kidneys and heart, respectively.

\section{Estimated economic loss}

\section{Direct loss}

The calculated mean annual slaughter rate is 5,636,364 heads of cattle. The mean retail price of bovine lung, liver, spleen, kidney, heart and a kilogram of beef is 10, 30, 3.6, 6.8, 9.2 and 68 ETB, respectively. These parameters and percent involvement of each organ were used in the estimation of the financial loss from organ condemnation. Accordingly, the estimated annual loss due to organ condemnation was: 
$\left(A S x C_{L u} \times P_{L u}\right)+\left(A S x C_{L i} X P_{L i}\right)+\left(A S X C_{S p} X P_{S p}\right)+\left(A S x C_{K i d} x P_{K i d}\right)+\left(A S X C_{H r} X P_{H r}\right)=$ $(5,636,364 \times 10 \times 27.98 \%)+(5,636,364 \times 30 \times 18.42 \%)+(5,636,364 \times 3.6 \times 1.71 \%)+(5,636,364 \times 6.8$ $x 1.22 \%)+(5,636,364 \times 9.2 \times 1.22 \%)=48364287 \boldsymbol{E T B}\left(2894072 \boldsymbol{U S D}^{1}\right)$

\section{Direct loss}

The loss from carcass weight decrease due to bovine hydatidosis is:

$A M P \times P f \times 5 \% \times C B f=652,631,579 \mathrm{~kg} \times 35.15 \% \times 5 \% \times 68 \mathrm{ETB} / \mathrm{kg}=\mathbf{7 7 9 ,} \mathbf{9 6 0}, \mathbf{0 0 0} \mathbf{E T B}(\mathbf{4 6 , 6 7 2 , 0 5 2}$ USD)

The loss from milk yield reduction is:

$A M \times M M Y \times$ Pf $x 10 \% \times C M=9,929,715 \times 498 \times 35.15 \% \times 10 \% \times 5=869,083,411$ ETB $(\mathbf{5 2 , 0 0 5 , 1 1 1}$ USD).

The total estimated economic loss from organ condemnation, carcass weight and milk yield decrease is thus 1,697,407,698 ETB (101,571,235 USD). This is equivalent to a loss of 475.40 ETB (28.45 USD) per every infected slaughtered cattle and 249.00 ETB (14.90 USD) per every infected milking cow.

\section{Discussion}

An annual infection prevalence of $35.15 \%$ bovine hydatidosis was found in the present study based on retrospective surveys previously conducted in 16 slaughterhouses located in different parts of Ethiopia. Comparable prevalence of bovine hydatidosis were reported in isolated recent studies in the country: 34.05\% from Bahir Dar (Nigatu Kebede et al., 2009), 32.11\% from Mekelle (Gebretsadik Berhe et al., 2010) and 29.69\% from Ambo (Endrias Zewdu et al., 2010). Slightly higher prevalence rates of $46.8 \%$ from Nazareth (Getaw et al., 2010) and $52.69 \%$ from Hawassa (Feyessa Regassa et al., 2010) were reported. A prevalence of $22.1 \%$ from Tigray region (Kebede, W. et al., 2009), $16.85 \%, 16 \%$ and $15.4 \%$ from Wolayita Sodo by Jemere Bekele and Berhanu Butako (2011), Nigatu Kebede et al. (2009) and Alemayehu Regassa et al., 2009 respectively, 15.2\% from Birre-Sheleko and Dangila Abattoirs (Nigatu Kebede et al., 2011) and $13.86 \%$ were also reported from 7 export abattoirs (Solomon Hailemariam, 1975). Studies in other countries reported prevalence of $31.6 \%$ from Niger (Arene, 1985) 48\% from Tanzania (Ernest et al., 2004), 6.6\% from Libya (Mohammed, 1985) and 8.28\% from Saudi Arabia (Ibrahim, 2010). In Greece, a prevalence of $82 \%$ was reported before the introduction of a control

1 The official exchange rate of 1 USD $=16.7115$ Ethiopian Birr (March 28, 2011) was used in this study 
program in 1984 that successfully reduced the prevalence to 0\% (Sotiraki et al., 2003). The difference in infection prevalence of bovine hydatidosis in different countries is a function of the control measures in place, animal husbandry practices, levels of education and economic status of the population and the farming community.

In the present study a total annual economic loss from organ rejection at postmortem as well as the indirect loss as a result of reduction in carcass weight and milk yield reduction due to bovine hydatidosis was reported based on the aggregated prevalence rate of cystic echinococcosis and the current retail market prices amounts to $1,691,266,200$ ETB (101,203,734 USD). This is equivalent to a loss of 475.40 ETB (28.45 USD) per every infected slaughtered cattle and 249.00 ETB (14.90 USD) per every infected milking cow. A prior study in Ethiopia estimated the loss of at least 20 USD per every hydatid infected subject (Yilma Jobre et al., 1996). Other studies in Ethiopia on direct and indirect economic loss from organ condemnation and reduced carcass weight were also conducted (Getaw et al., 2010; Endrias Zewdu et al., 2010; Nigatu Kebede et al., 2011). Estimated global annual overall losses from the burden of human cystic echinococcosis and livestock-associated losses were reported to be $\$ 1,918,318,955$ and $\$ 2,190,132,464$, respectively (Budke et al., 2006). The overall economic loss attributable to cystic echinococcosis in humans and animals in 2005 in Spain was estimated at 148,964,534 euros (€) (Benner et al., 2010). An estimated nation-wide annual economic loss of US\$ 32.4 million from Turkey (Sariozkan and Yalcin, 2009) and 10.8 million $€$ from Greece (Tsaglas, 1985) were also reported due to hydatidosis. Annual economic loss of U.S. $\$ 903,649$ (95\% CI U.S. $\$ 717,158-1,113,354)$ from discarded livers, decreased reproduction, and decreased carcass weight in sheep, goats, and yaks was reported in addition to decreased value of sheep and yak hides where a loss of U.S.\$8.44 per individual infected yak due to discarded liver alone was also estimated (Budke et al., 2005). Differences between the quantities of losses amongst the countries could be due to different livestock population, prevalence rates, methodologies employed, input parameters measured for the analyses, differences in productivity of animals and retail prices. The indirect loss accounts for $97.5 \%$ of the total cost associated with bovine hydatidosis, whereas the direct losses were $2.5 \%$. This is in general agreement with the reported $99 \%$ of the total loss associated with indirect loss (Benner et al., 2010)

Ethiop. Vet. J., 2012, 16(2), 1-14 
The present study demonstrated that bovine hydatidosis is widespread and a highly prevent parasitic disease in Ethiopia inflicting considerable direct and indirect economic loss (nearly 100 million USD per year) from organ condemnation, decreased carcass weight and reduced milk yield. The figure would have been much bigger if other input parameters such as mortality, losses from reduced work efficiency, reduced fecundity and burden on the public health were measured and considered in the economic estimation. This study is a graphic illustration of the importance of endoparasitism on the productivity of livestock in Ethiopia, a sector that hardly receives attention by the veterinary services. The new 'One Health' initiative is about effectively dealing with zoonotic disease entities by bringing public and animal health actors to improve epidemiological understanding and packaging interventions in the animal-human-environment interfaces.

The magnitude of loss per infected subject warrants the need to mount an integrated nation-wide hydatidosis control program involving public education, canine health care, proper handling and disposal of infected organs, stray dog population management and institution of strict standard operating procedures (SOPs) in slaughterhouses and public health legislative reinforcements. The authors recommend that hydatidosis control program should be designed and implemented in the context on 'One Health' initiative by integrating it with other zoonotic disease control program and in partnerships with animal and public health actors as well as other relevant stakeholders.

\section{References}

Abdel-Hafez, S.K, and A1-Yaman, F.M, 1989. Spleen Hydatidosis in sheep from North Jordan, Vet. Parasitol. 30, 191-196.

Ahmadi, N.A. and Meshkehkar, M., 2011. An abattoir-based study on the prevalence and economic losses due to cystic echinococcosis in slaughtered herbivores in Ahwaz, south-western Iran. J. Helminthol., 85, 33-39.

Ahmed, A, 1988. Hydatidosis prevalence at Jimma abattoir. DVM Thesis. Addis Ababa University, Faculty of Veterinary Medicine, Debre Zeit, Ethiopia, Pp25

Alyie, M., 1988. Study on prevalence and economic significance of bovine hydatidosis in Gamogofa region. DVM thesis, Addis Ababa University, Faculty of Veterinary Medicine, Debre Zeit, Ethiopia, pp29. 
Arene, F.O.I., 1985. Prevalence of hydatid cysts in domestic livestock in the Niger Delta. Trop. Anim. Hlth. Prod., 17, 3-5.

Asfaw, Y. 1989. Hydatidosis in cattle, sheep, pigs, Cysticercus tenuicolis in sheep around Dessie and efficancy of Hagenia abyssinica (Kosso) on Taenia hydatigena. DVM Thesis. Addis Ababa University, Faculty of Veterinary Medicine, Debre Zeit, Ethiopia, pp27.

Behnke, R., 2010. The Contribution of Livestock to the Economies of IGAD Member States. Study Findings, Application of the Methodology in Ethiopia and Recommendations for Further Work. A Living from Livestock, IGAD Livestock Policy Initiative Working Paper No. 02 - 10

Bekele, J. and Butako, B., 2011. Occurrence and financial loss assessment of cystic echinococcosis (hydatidosis) in cattle slaughtered at Wolayita Sodo municipal abattoir, Southern Ethiopia. Trop. Anim. Hlth. and Prod., 43(1), 221-228

Beller, K.A., 1977. The control of helminthes: an economic necessity. The blue book for Veterinary Profession. 27, 1-4.

Benner, C., Carabin, H., Sánchez-Serrano, L.P., Budke, C.M. \& Carmena, D., 2010. Analysis of the economic impact of cystic echinococcosis in Spain. Bull World Hlth Organ., 88, 49-57

Berhe, G., Tadesse, G, Kiros, H. and Negus, A., 2010. Concurrent infection of hydatidosis and fasciolosis in cattle slaughtred at Mekelle Municipal abattoir, Tigray Region. Ethiop. Vet. J. 14(2), 39-49.

Binegde, G., 1988. A preliminary survey on echinococcosis/hydatidosis in livestock (cattle, sheep, goats, and pig) slaughtered at Addis Ababa abattoir. DVM Thesis. Addis Ababa University, Faculty of Veterinary Medicine, Debre Zeit, Ethiopia, pp23.

Budke, C.M., Deplazes, P. and Torgerson P.R., 2006. Global socioeconomic impact of cystic echinococcosis. Emerging Infectious Diseases. Emerging Infectious Diseases, 12, 296-303.

Budke, C.M., Jiamin, Q., Qian, W. and Torgerson, P.R., 2005. Economic effects of echinococcosis in a disease-endemic region of the Tibetan plateau. Am. J. Trop. Med. Hyg., 73(1), 2-10. 
Demeke, G., 1987. Incidence of bovine echinococcosis at Melgue Wondo abattoir and the role of dogs, jackals and hyena in the transmission around Awassa and Wondogenet. DVM Thesis. Addis Ababa University, Faculty of Veterinary Medicine, Debre Zeit, Ethiopia, pp21.

Ernest, E. Kassuku, A., Kazwala, R., 2004. Studies on the epidemiology of echinococcosis/ hydatidosis in Ngorongoro district, Arusha region, Tanzania. Int. Arch. Hydatid. 35,43 .

Ferede, D., 1996. Economic importance of organ condemnation due to fasciolosis and hydatidosis in cattle and sheep slaughtered at Dire Dawa abattoir. DVM Thesis. Addis Ababa University, Faculty of Veterinary Medicine, Debre Zeit, Ethiopia, Pp30.

Gesese, N., 1990. Study of hydatidosis/echinococcosis in cattle slaughtered at Bahr Dar Municipality abattoir. DVM Thesis. Addis Ababa University, Faculty of Veterinary Medicine, Debre Zeit, Ethiopia, pp24.

Getaw, A,. Beyene, D., Ayana D., Megersa B., Abunna, F., 2010. Hydatidosis: Prevalence and its economic importance in ruminants slaughtered at Adama municipal abattoir, Central Oromia, Ethiopia. Acta Trop., 113, 221-225.

Gidey, Y., 1990. Preliminary study on echinococcosis/hydatidosis in ruminants slaughtered at Nazareth abattoir, D.V.M Thesis. Addis Ababa University, Faculty of Veterinary Medicine, Debre Zeit, Ethiopia, pp27.

Goshime, A., 1996. Prevalence and economic significance of hydatidosis or echinococcosis in slaughtered cattle, sheep and goats in South Wollo. DVM Thesis. Addis Ababa University, Faculty of Veterinary Medicine, Debre Zeit, Ethiopia, pp36.

Hailemariam, S.,M., 1975 A brief analysis of activity of the meat inspection and quarantine division. Department of veterinary services, pp128.

Hailemelekot, M., 1995. Bovine hydatid disease: an assessment trial of its prevalence and economic importance at Bahr Dar Municipality abattoir. DVM Thesis. Addis Ababa University, Faculty of Veterinary Medicine, Debre Zeit, Ethiopia, Pp32.

Heath, D., Yang, W., Li, T., Xiao, Y., Chen, X. and Huang, Y. et al., 2006. Control of hydatidosis. Parasitol. Int., 55, 247-252 
Ibrahim, M.M., 2010. Study of cystic echinococcosis in slaughtered animals in Al Baha region, Saudi Arabia: Interaction between some biotic and abiotic factors. Acta Trop., 113, 26-33.

ILCA , 1979. Trypanotolerant livestock in West and central Africa: Volume 1. General study. ILCA Monograph 2, ILCA, Addis Ababa, Ethiopia. pp 147.

Jelal, A., 1992. Economic significance of bovine fasciolosis and hydatidosis at Soddo abattor, DVM Thesis. Addis Ababa University, Faculty of Veterinary Medicine, Debre Zeit, Ethiopia, Pp 23.

Jember, G., 1991. The prevalence of hydatidosis in cattle at Awassa abattoir. DVM Thesis. Addis Ababa University, Faculty of Veterinary Medicine, Debre Zeit, Ethiopia, pp23.

Jenkins, D. J., Romig, T. \& Thompson, R. C. A. 2005. Emergence/re-emergence of Echinococcus spp.—a global update. Int. J. Parasitol. 35, 1205-1219.

Jobre Y, Lobago F, Tiruneh R, Abebe G, Dorchies P., 1996. Hydatidosis in three selected regions in Ethiopia: an assessment trial on its prevalence, economic and public health importance. Revue Méd. Vét., 147 : 797-804

Kebede, N., Gebre-Egziabher, Z., Tilahun, G. and Wossene, A., 2011. Prevalence and Financial Effects of Hydatidosis in Cattle Slaughtered in Birre-Sheleko and Dangila Abattoirs, Northwestern Ethiopia. Zoonoses Public Hlth., 58, 41-46.

Kebede, N., Mekonnen, H., Wossene A. and Tilahun, G., 2009. Hydatidosis of slaughtered cattle in Wolaita Sodo Abattoir, southern Ethiopia. Trop. Anim. Hlth. and Prod., 41(4), 629-633

Kebede, N., Mitiku, A. and Tilahun, G., 2009. Hydatidosis of slaughtered animals in Bahir Dar Abattoir, Northwestern Ethiopia. Trop. Anim. Hlth. and Prod., 41(1), $43-50$

Kebede, W., Hagos, A., Girma Z. and Lobago, F., 2009. Echinococcosis/hydatidosis: its prevalence, economic and public health significance in Tigray region, North Ethiopia. Trop. Anim. Hlth. and Prod., 41(6), 865-871.

Lemma, A., 1990. The prevalence of hydatidosis in cattle, sheep and goats and echinococcus granulosus in dogs in Arsi administrative region, DVM Thesis. Addis Ababa University, Faculty of Veterinary Medicine, Debre Zeit, Ethiopia, Pp26. 
Lobago, F. 1994. Echinococcosis/hydatidosis in Konso (southern Ethiopia) an assessment trail of its prevalence, economic and public health importance. DVM Thesis. Addis Ababa University, Faculty of Veterinary Medicine, Debre Zeit, Ethiopia, pp42.

Melkamu, T., 1986. A preliminary study on echinococcosis/hydatidosis of livestock (cattle, sheep and dogs) in Gondar administrative region. DVM Thesis. Addis Ababa University, Faculty of Veterinary Medicine, Debre Zeit, Ethiopia, pp286.

Mendy, R.M., 1975. Hydatid zoonosis. Vet. Med. Rev., 1, 176-191.

Mengistu, A, 2006. Country Pasture/Forage Resource Profiles. Available at www.fao. org/ag/AGPC/doc/Counprof/Ethiopia, accessed on March 11, 2011

Mersie, A., 1985. A survey of econococcus and its public health significance in Soddo abattoir, DVM Thesis. Addis Ababa University, Faculty of Veterinary Medicine, Debre Zeit, Ethiopia, Pp28.

Mohammed, A.A., 1985. Prevalence of Echinococcus granulosus among domestic animals in Libya. Trop. Anim. Hlth. Prod., 17, 169-170.

Mulugeta, , 1987. A preliminary study on echinococcosis/hydatidosis in Harrargie region and the efficacy of Glinus Lotoides seeds against Echinococcus granulosus, in pups infected experimentally with hydatid materials. DVM Thesis. Addis Ababa University, Faculty of Veterinary Medicine, Debre Zeit, Ethiopia, pp30.

Olika, F., 1997. Study on prevalence and economic significance of hydatidosis in ruminants and echinococcus granulosus in dogs in and around Assela. DVM Thesis. Addis Ababa University, Faculty of Veterinary Medicine, Debre Zeit, Ethiopia, pp49.

Polydorou, K., 1981. Animal health and economics. Case study: echinococcosis with reference to Cyprus. Bul. Int. Epz., 93, 981-992.

Regassa, A., Abunna, F., Mulugeta A. and Megersa B., 2009. Major metacestodes in cattle slaughtered at Wolaita Soddo Municipal abattoir, southern Ethiopia: Prevalence, cyst viability, organ distribution and socioeconomic implications. Trop. Anim. Hlth. and Prod., 41(7), 1495-1502

Regassa, F., 1987. Prevalence of hydatidosis in Nekempte municipality slaughterhouse. DVM Thesis. Addis Ababa University, Faculty of Veterinary Medicine, Debre Zeit Ethiopia, pp26. 
Regassa, F., Molla, A. and Bekele, J., 2010. Study on the prevalence of cystic hydatidosis and its economic significance in cattle slaughtered at Hawassa Municipal abattoir, Ethiopia. Trop. Anim. Hlth. Prod., 42(5), 977-984.

Robinson, M.W. and Dalton, J.P., 2009. Zoonotic helminth infections with particular emphasis on fasciolosis and other trematodiases. Phil. Trans. R. Soc. B. 364, 27632776

Romazanov, V.T., 1983. Evaluation of economic losses due to echinococcosis. In: Lysendo A, (Ed.), Zoonosis control: collection of teaching aids for international training course vol. II. Moscow: Centre of International Projects GKNT, pp 283-85.

Sariozkan, S. and Yalcin, C., 2009. Estimating the production losses due to cystic echinococcosis in ruminants in Turkey. Vet. Parasitol., 163, 330-334.

Shiferaw, D., 1992. Economic significant of bovine hydatidosis, fasciolosis and cysticercosis. DVM Thesis. Addis Ababa University, Faculty of Veterinary Medicine, Debre Zeit, Ethiopia, Pp30.

Sinishaw, W., 1988. Prevalence of cattle hydatidosis and its economic significance in Robe municipality abattoir. DVM Thesis F.V.M., A.A.U., Debre Zeit, Ethiopia, pp35.

Sirak, A., 1996. Cause of organ condemnation at the Bahr Dar abattoir. Proceedings of the 10th conference of Ethiopia Veterinary Association, pp 104-104.

Sotiraki, S., Himonas, C. and Korkoliakou, P., 2003. Hydatidosis-echinococcosis in Greece. Acta Trop., 85, 197-201

Tadesse, T., 1995. Epidemiology of bovine fasciolosis and hydatidosis in Debre Berhan region. DVM Thesis, F.V.M., Debre Zeit, Ethiopia, pp56.

Tiruneh, R., 1987. Study on economic significance of bovine fascioosis and hydsatidosis at Gondar abattoirs. DVM Thesis. Addis Ababa University, Faculty of Veterinary Medicine, Debre Zeit, Ethiopia, pp36.

Tsaglas, E., 1985. The epidemiological situation of the most important zoonoses in man and animals in Greece. Bull. Hell. Vet. Soc., 36(1), 45-54.

Yewondwossen, M., 2011. Fresh meat New countries buy Ethiopian. Capital News, 13 (640). 
Yhidego, H., 1997. Hydatidosis/echinococcosis: prevalence and economic impact in bovine at Mekele Municipal abattoir, zoonosis and infection in dogs (Mekele Tigray). DVM Thesis. Addis Ababa University, Faculty of Veterinary Medicine, Debre Zeit, Ethiopia, pp35.

Zewdu, E., Teshome, Y. and Wakwoya, A., 2010. Bovine hydatidosis in Ambo Municipality abattoir, West Shoa, Ethiopia. Ethiop. Vet. J., 14(1), 1-14. 